\title{
Use of twitter data for waste minimisation in beef supply chain
}

\author{
Nishikant Mishra ${ }^{1} \cdot$ Akshit Singh $^{1}$
}

Published online: 28 September 2016

(c) The Author(s) 2016. This article is published with open access at Springerlink.com

\begin{abstract}
Approximately one third of the food produced is discarded or lost, which accounts for 1.3 billion tons per annum. The waste is being generated throughout the supply chain viz. farmers, wholesalers/processors, logistics, retailers and consumers. The majority of waste occurs at the interface of retailers and consumers. Many global retailers are making efforts to extract intelligence from customer's complaints left at retail store to backtrack their supply chain to mitigate the waste. However, majority of the customers don't leave the complaints in the store because of various reasons like inconvenience, lack of time, distance, ignorance etc. In current digital world, consumers are active on social media and express their sentiments, thoughts, and opinions about a particular product freely. For example, on an average, 45,000 tweets are tweeted daily related to beef products to express their likes and dislikes. These tweets are large in volume, scattered and unstructured in nature. In this study, twitter data is utilised to develop waste minimization strategies by backtracking the supply chain. The execution process of proposed framework is demonstrated for beef supply chain. The proposed model is generic enough and can be applied to other domains as well.
\end{abstract}

Keywords Big data Beef supply chain . Waste minimisation $\cdot$ Twitter analytics

\section{Introduction}

World population will be around 9 billion by 2050. Huge amount of resources will be needed to feed these enormous amounts of people. There are millions of people losing their lives globally because of hunger on daily basis. On the other hand, one third of the food produced globally is lost within the supply chain or get wasted at the consumer end (Food and Agricul-

$凶$ Nishikant Mishra

n.mishra@uea.ac.uk

Akshit Singh

akshit.singh@uea.ac.uk

1 Norwich Business School, University of East Anglia, Norwich, UK 

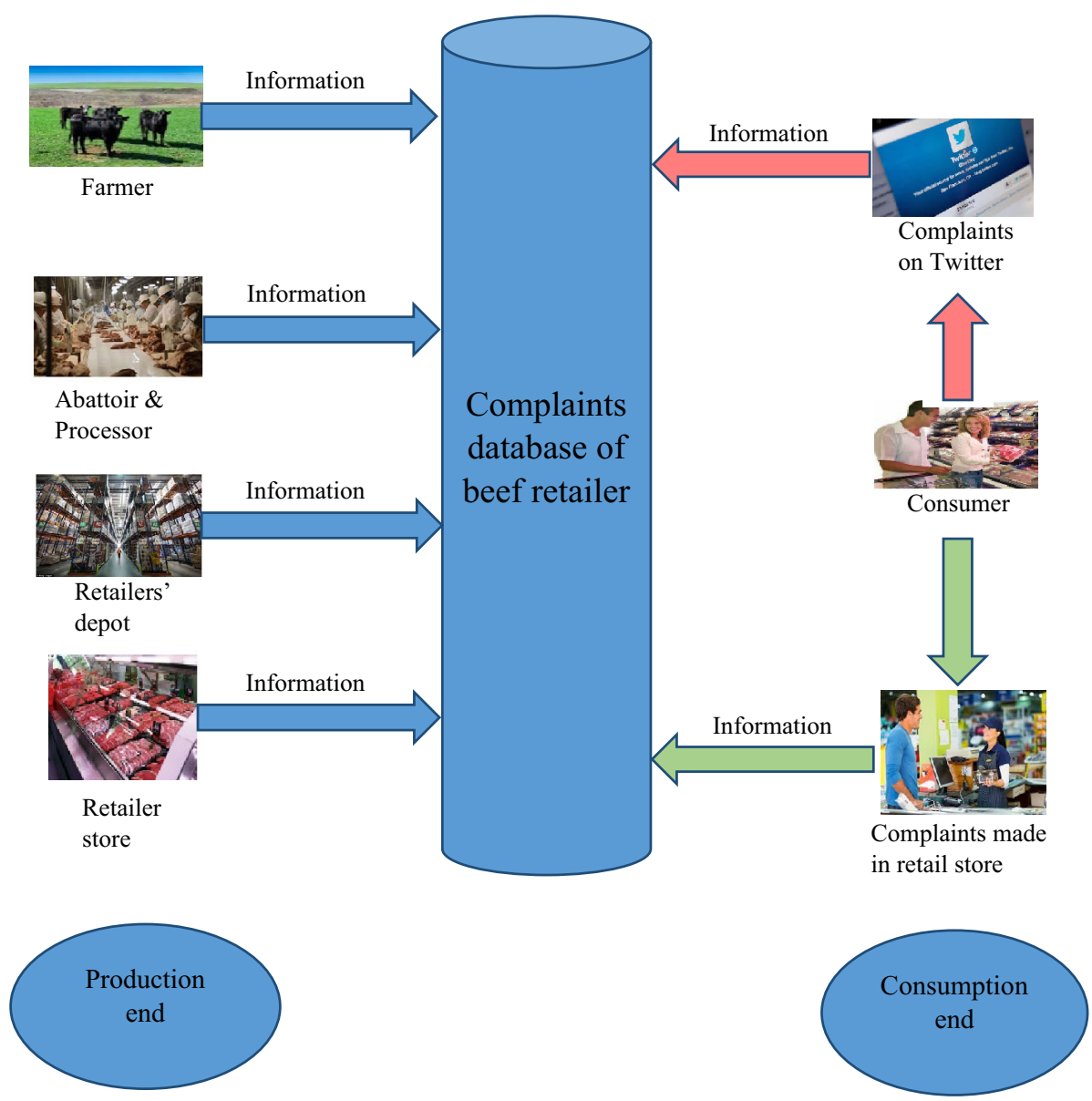

Fig. 1 Various ways of receiving waste related information for beef retailer

ture Organization of the United Nations). This food waste is worth around US \$ 680 billion per year in developed countries and approx. US \$ 310 billion per year in developing countries (Save Food 2015). All the stakeholders of the food supply chain: farmers, wholesalers, logistics, retailers and consumers have the onus of food waste. Waste might be generated at one end in the supply chain and their root cause might be linked to other segment of the supply chain. For example, if the beef gets discoloured before its sell by date, it may be because of the lack of vitamin E diet fed to the cattle in the beef farms (Liu et al. 1995). Different segments of food supply chain are generating various kinds of waste. Food retailer chains are facing enormous pressure from government legislation, competition from rival brands, sustainable production etc. to minimise the waste in their supply chain. Every day, retailers are collecting enormous amount of data from farmers, abattoir and processors, retailers and consumers as shown in Fig. 1. These data can be utilised to increase the efficiency and minimise the waste. In literature, various methodologies such as six sigma (Nabhani and Shokri 2009), lean principles (Cox and Chicksand 2005), value chain analysis (Taylor 2006), etc. have been developed to address various issues at farmer, processor and retailer end. The maximum amount of waste is being generated at the consumer end. Retailers are 
trying to utilise the complaints made by consumers in the retail store for waste minimisation. Majority of the customers don't leave the complaints in the store because of various reasons like inconvenience, lack of time, distance, ignorance etc. Therefore, only limited information is available in the retailer stores about the issues faced by consumers, which are leading to food waste. Social media have now become the part and parcel of everyone's life to express their opinions. Many of the customers who are not pleased with food products leave their complaints on the social media every day. These information are enormous and scattered in nature and resembles to the salient features of big data i.e. volume, variety, velocity (Wang et al. 2016; Shuihua et al. 2016; Song et al. 2016; Tayal and Singh 2016) as mentioned below:

1. Volume-Great volume of data, which required big storage or contain large number of records or information. At present, there are 310 million active users on twitter, who are freely expressing their concern (Twitter Usage Statistics 2016).

2. Velocity-Data generate with high frequency. On an average, 500 million tweets related to different topics are tweeted every day (Twitter Usage Statistics 2016).

3. Variety-Data gathered from different sources, format and/or having multidimensional data fields. Consumers express their attitude, sentiments, opinions and thoughts in the form of unstructured data i.e. text, tweets, posts, pictures and videos.

During the study, it was found that on an average, 45,000 tweets are made every day, which are related to beef products. These tweets consist of various quality attributes and problems associated with beef products like flavour, rancidity, discoloration, presence of foreign body, etc. These data can be utilised by retailer to identify the root causes of waste and consequently help in developing waste minimisation in longer term. However, the nature of consumer complaints on social media is quite vague and unstructured. In literature, there was no framework available to link them to root causes of waste in different segments of supply chain. In this article, architecture is proposed to collect and analyse information from twitter and consequently link them to the root causes of food waste in the supply chain.

The organisation of the article is as follows: Sect. 2, consists of literature review of research work done in the domain of big data and food waste in the supply chain. Section 3, consists of beef supply chain and social media data. Section 4, comprises of twitter analytics framework. Section 5, demonstrates the implementation of the framework on beef supply chain. Section 6, includes managerial implications of the framework. Finally, the article is concluded in Sect. 7.

\section{Literature review}

Food waste is occurring at different stages of the supply chain from farms to the retailer. Various techniques have been employed in the past to address this issue by identifying the root causes of food waste and consequently mitigating them such lean principles (Cox and Chicksand 2005), value chain analysis (Taylor 2006), six sigma (Nabhani and Shokri 2009), and just in time principle. Cicatiello et al. (2016) have explored the waste occurring at retailer end and its environmental, economic and social implications. The data collected from an Italian supermarket project was utilized to develop food waste recovery strategy. In this research both physical and monetary value of food was considered. Mena et al. (2011) have found out the principal causes leading to food waste in the supplier retailer interface. The management practices of UK and Spain have been compared using current reality tree method. Various good practices such as efficient forecasting, shelf life management, promotion management, 
cold chain management and proper training to employees, etc. have been suggested to mitigate the root causes of waste. Katajajuuri et al. (2014) has quantified the amount of avoidable waste occurring in the food production and consumption chain in Finland. It was found that households were creating 130 million $\mathrm{Kg}$ of food waste per year. The waste occurring in food service sector is about $75-85$ million kg per year. The whole food industry in Finland was producing waste of 75-140 million kg per annum. It was concluded that overall 335-460 million $\mathrm{kg}$ of waste is generated in the finish food chain (excluding farming sector). Francis et al. (2008) have employed value chain analysis technique to evaluate UK beef sector. Waste elimination strategy was developed at producer and processor level in UK beef supply chain by comparing them with Argentine counterparts. Also, good management practices are proposed to minimise the waste.

The majority of waste in beef supply chain is generated at the consumer end. Waste is generated by various issues such as discolouration of beef products prior to expiry of shelf life (Jeyamkondan et al. 2000), lack of tenderness (Goodson et al. 2002; Huffman et al. 1996), presence of extra fat (Brunsø et al. 2005), oxidisation of beef (Brooks 2007), presence of foreign bodies in beef products (FSA 2015) and inefficient cold chain management (Kim et al. 2012; Mena et al. 2011). These root causes are occurring at consumer end because of the issues within the beef supply chain. For instance, discoloration of beef could be due to lack of vitamin $\mathrm{E}$ in the diet of cattle (Liu et al. 1995; Houben et al. 2000; Cabedo et al. 1998; O'Grady et al. 1998; Lavelle et al. 1995; Mitsumoto et al. 1993) and temperature abuse of beef products along the supply chain (Rogers et al. 2014; Jakobsen and Bertelsen 2000; Gill and McGinnis 1995; van Laack et al. 1996; Jeremiah and Gibson 2001; Greer and Jones 1991). Lack of tenderness is because of absence or inefficient maturation of carcass from which beef products are derived (Riley et al. 2005; Vitale et al. 2014; Franco et al. 2009; Gruber et al. 2006; Monsón et al. 2004; Sañudo et al. 2004; Troy and Kerry 2010). Presence of extra fat could be due to cattle being not raised as per the weight and conformation specifications of the retailer (Hanset et al. 1987; Herva et al. 2011; Borgogno et al. 2016; AHDB Industry Consulting 2008; Boligon et al. 2011) and inefficient trimming procedures in the boning hall in abattoir (Francis et al. 2008; Mena et al. 2014; Kale et al. 2010; Watson 1994; Cox et al. 2007). The oxidisation of beef could be occurring because of improper packaging at abattoir and processor, damage of packaging along the supply chain and inappropriate packaging technique being followed (Brooks 2007; Lund et al. 2007; Singh et al. 2015). The presence of foreign bodies could be due to improper packaging because of machine error at abattoir and processor, lack of safety checks such as metal detection, physical inspection and lack of renowned food safety process management procedures being followed such as HACCP (Goodwin 2014). The inefficient cold chain management could be because of lack of periodic maintenance of refrigeration equipment (Kim et al. 2012).

In literature, various mechanisms have been developed to analyse big data to mitigate various challenges, bottlenecks in the supply chain. Chae (2015) and Hazen et al. (2016) have suggested a mechanism of twitter analytics for analysis of tweets in the domain of supply chain management. They have attempted to develop an understanding of prospective role of Twitter in the practice of supply chain management and future research. This framework consists of three techniques called descriptive analysis, content analysis and network analysis. It was found that supply chain tweets are being utilised by various professional associations like news services, logistics companies etc. for numerous reasons like recruitment of employees, sharing of information, etc. It was observed that some of the tweets were conveying strong sentiments with regards to risk, environmental impact, sales etc. of certain corporations. Tan et al. (2015) proposed a big data analytic framework for business firms. It is based on deduction graph method. The case study has demonstrated the competitive advantage achieved by 
business enterprises by analysing big data using the proposed framework. Consequently, the supply chain innovation capabilities of these firms were also being improved. Hazen et al. (2014) identified the issues with data quality in the domain of supply chain management. Innovative techniques for data monitoring and controlling their quality were proposed. The significance of data quality in research and practice of supply chain management has been described. Vera-Baquero et al. (2016) have proposed a cloud-based framework using big data techniques to enhance the performance analysis of businesses efficiently. The capability of the mechanism was demonstrated to deliver business activity monitoring in big data environment in real time with minimal cost of hardware. Frizzo- Barker et al. (2016) have done a literature review of big data associated publications in business journals. The time period of the publications was from year 2009 to year 2014 and 219 peer reviewed research articles from 152 business journals were examined. Quantitative and qualitative analysis was performed using NVivo10 software. The biggest advantages and challenges of implementing big data in domain of business were found out. It remains fragmented and has lots of potential in terms of theoretical, mathematical and empirical research. In literature, it was found that research on big data in domain of business is in preliminary stage. In the past, several researches have been conducted to use social media information in food industry particularly for marketing purposes (Rutsaert et al. 2013; Kaplan and Haenlein 2011; Thackeray et al. 2012). However, big data analytics can be utilised to minimise the waste in food supply chain.

At present, retailers are utilising the big data analytics for waste minimisation by using consumer complaints made in retail store. However, lots of useful information available at social media data, which can be utilised for waste minimisation. Consumer complaints on social media are vague and unstructured in nature. In literature, there was no mechanism available to link social media data with root causes of waste. In this article, architecture has been developed for above-mentioned process. In the upcoming sections, beef supply chain and social media data is explained in detail.

\section{Beef supply chain and social media data}

The schematic diagram of beef supply chain is shown in Fig. 2. Cattle are raised in the beef farms from age of 3 months to thirty months depending upon breed and demand in the market.

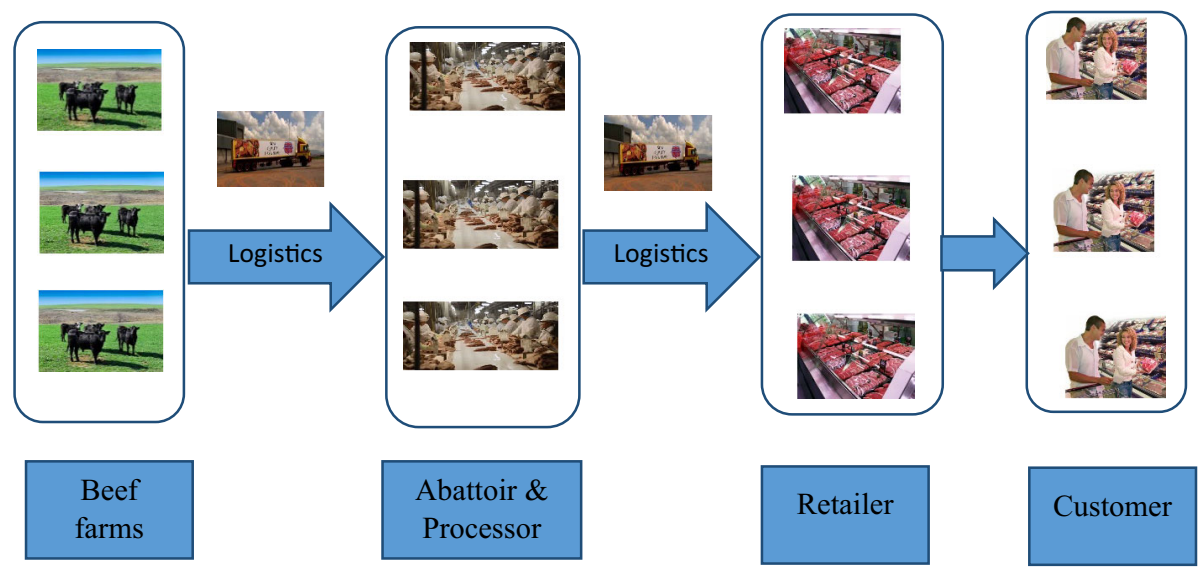

Fig. 2 Product flow in beef supply chain 
When they approach their finishing age, they are sent to abattoir and processor. Cattle are butchered, boned and processed into various beef products like mince, steak, burger, joint, dicer/ strifry, etc. Then, the processed products are packed and labelled. The final products are sent to retailer. Consumers expect their beef products to be of high quality in terms of flavour, texture, colour, tenderness, smell, etc. For instance, customers usually desire fresh red colour beef products. If the beef products are not fresh red colour then customers discard them and express these issues on twitter using keywords like beef was having odd colour, beef got discoloured, beef was grey in colour, etc. Similarly, the beef products are expected to be tender when cooked. If they are hard to chew even after cooking, customers gets upset and mention this issue on twitter using phrases like beef was very chewy. Customers don't expect unpleasant smell in their beef products. If bad smell is associated with their beef products, customers discard the beef products and post on twitter comments like the beef was too rancid, beef smells awful, etc. Sometimes, a foreign body like plastic is found in the beef products. In beef industry, various quality assurance and food safety guidelines are available to overcome above mentioned quality and safety issues, which are explained in next subsection.

\subsection{Safety checks and quality assurance by regulatory authorities}

There are various safety checks and quality assurance procedures followed by regulatory bodies at various stages in beef supply chain. For instance, at beef farms, regular checks are being made to ensure that cattle are being raised as per strict farm assurance schemes, which examines their diet, housing, hygiene, veterinary checks, animal welfare, environmental protection, etc. (Food Standards Agency 2012a). The logistics vehicles used for transportation of cattle are also being monitored by regulatory authorities to ensure if there is ample space allowance provided to each cattle, appropriate ramp angle is maintained for loading/unloading of cattle and the journey time does not exceed from the maximum journey time allowed by government authorities (Red 2011). In the abattoir and processor, application of renowned safety management practice like HACCP is performed at all stages viz. slaughtering, boning and processing into beef products like mince, burger, steak, etc (Meat Industry Guide 2015a). It ensures the food safety, hygiene and quality of beef products made at abattoir and processor (Sofos et al. 1999). The logistics vehicle deployed for transfer of beef products from abattoir and processor to retailer is critically evaluated in terms of hygiene and cold chain efficiency (Meat Industry Guide 2015b). Finally, the quality checks are performed at retailer if they are purchasing beef from an accredited supplier by the regulatory body, random sampling is performed to make sure that the beef products are edible and cold chain management is evaluated (Food Standards Agency 2012b). There are certain quality assurance schemes available, which monitor the meat from farm to fork and ensure that it has gone through the highest standards of food safety and quality assurance. For example, Red tractor scheme in the UK, which maps the whole beef supply chain for quality assurance and food safety (Food Standards Agency 2012a). The beef products produced under this scheme carries red tractor logo so that consumers are assured of their quality attributes. Despite of the aforementioned quality assurance and food safety checks, sometimes, consumers are receiving beef products of substandard quality. It leads to customer dissatisfaction. They also express their concern and issue on social media. This information can be analysed to identify the root causes of waste in the beef supply chain. The next section includes how the customer's tweets have been utilised to develop waste minimisation strategy using twitter framework. 


\section{Twitter analytics framework}

Extracting data from Twitter involves recognition of domain of interest by utilisation of hashtags and keywords. APIs are needed for the data collection. It consists of mining 1\% of publicly available data. Twitter data can also be acquired via data providers or twitter firehoses like GNIP, who can provide access to $100 \%$ of data depending on their guidelines. However this is an expensive approach. API services are available for other social media as well. For instance, Marketing API, Atlas API can be used for Facebook. In this article, we have used publically available data for our analysis purpose.

To access twitter-streaming API, information such as API key, API secret, access token and access token secret is required, which can be obtained from https://apps.twitter.com/. The output from the twitter streaming API is in the JSON (JavaScript Object Notation) format. This format makes it easier to read the social media postings in twitter and it also allows machine to parse it. In this article, the twitter streaming API configurations is used to store/append twitter data in a text file. Then, a parsing method is implemented to extract datasets relevant to this study (e.g. tweets, coordinates, hashtags, urls, retweet count, follower count, screen name and others). The output data of the parsing method was stored in the Comma Separated Values (CSV) file. The collected data were unstructured (like informal expressions), more sophisticated (like URL, hashtags, etc.) as compared to the conventional data (like profit data) stored in database of multinational firms. To extract the useful information from this data, sentiment analysis, descriptive analysis, content analysis are being performed. Thereafter, the result of analysis are linked with the root causes of waste. The detailed description of the proposed framework is depicted in Fig. 3.

\subsection{Sentiment analysis}

Tweets consist of information as well as sentiments. Therefore, advanced text mining techniques are necessary for opinion gathering. Sentiment analysis could be performed at two levels: to the whole set of tweets collected and to various regions based extracted tweets. The main goal is to classify them as positive, negative and neutral tweets.

Sentiment analysis is defined as a research domain that examines public's appraisals, emotions, attitudes, sentiments, opinions towards numerous aspects, such as corporations, products, problems, subjects and their associated features, services. It represents a wide area of issues. Multiple names are available with slightly distinguished activity like sentiment mining, opinion mining, sentiment analysis, emotion analysis, review mining, opinion extraction, subjectivity analysis and affect analysis. However, all the aforementioned names belong to the broad area of sentiment analysis or opinion mining. While the corporate world employs the term sentiment analysis, the academic world utilises both opining mining and sentiment analysis. Both the terms represents the same research area. Nasukawa and Yi (2003) were the first researcher to mention the term sentiment analysis in literature whereas opinion mining was first cited by Dave et al. (2003). The first research on sentiments and opinions was performed by Das and Chen (2001).

Dictionary is powerful tool to collect sentiment words as most of them (such as WordNet) offer synonyms and antonyms for each word (Miller et al. 1990). Hence, the basic technique in this method is to use certain sentiment words seeds to bootstrap based on synonyms and antonyms arrangement of the dictionary. Initially, a small set of sentiment words or seeds with well-defined positive and negative orientation is manually collected. Then, the algorithm increases this set via searching for their respective synonyms and antonyms in 


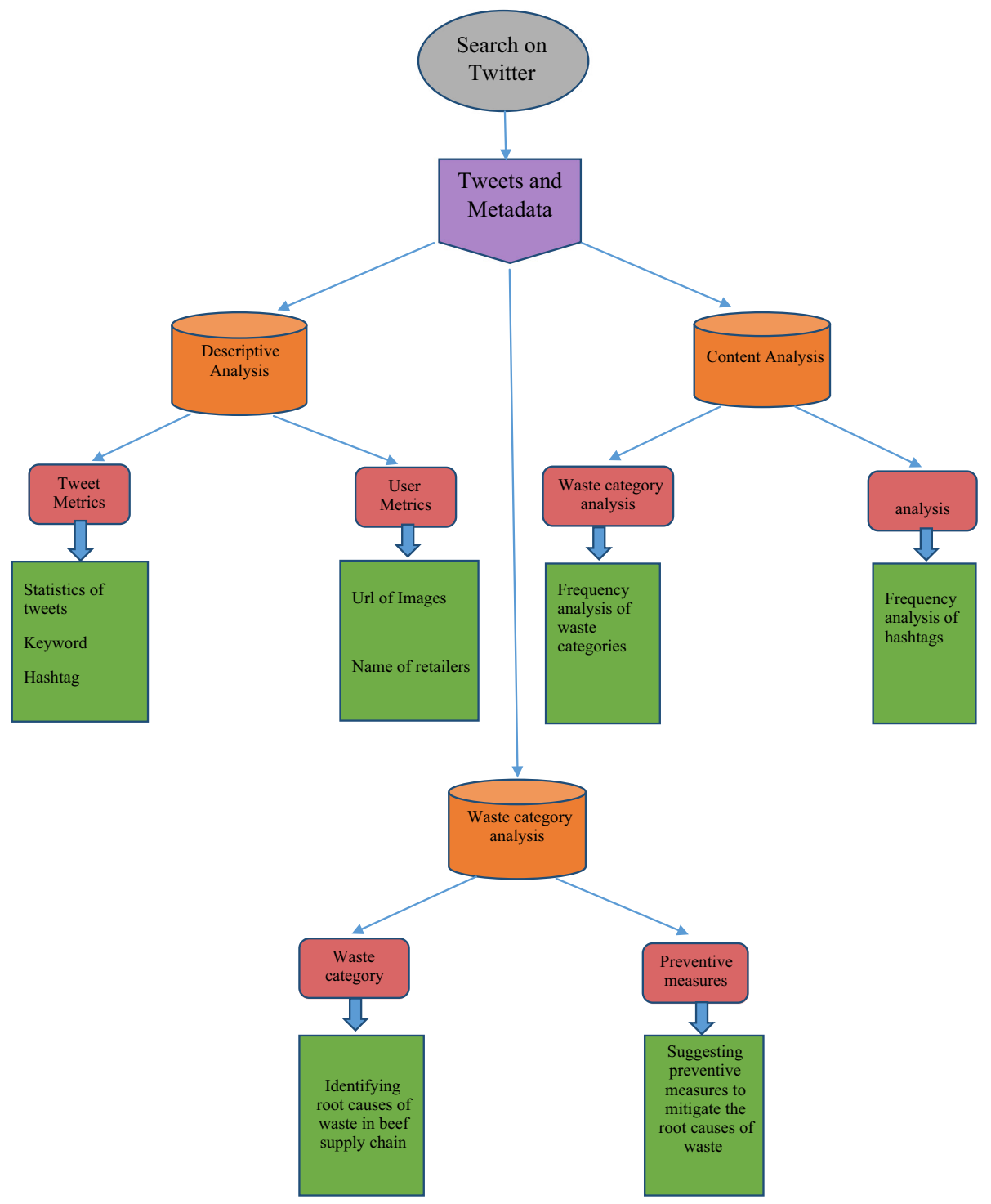

Fig. 3 Twitter analytics framework

the online dictionary like WordNet. The new words searched are combined to the small set. Then, next iteration is initiated. When the search is complete and there no new words being found out, then the iterative process is concluded. This method was followed by $\mathrm{Hu}$ and Liu (2004), who suggested a dictionary based algorithm for the sentiment categorisation at aspect level. This technique can calculate sentiment even at the sentence level. It originated from sentiment dictionary developed by using a bootstrapping technique, certain positive and negative sentiment word seeds and the synonym and antonyms relationship in WordNet dictionary. The sentiment scores of all sentiment words present in a sentence or segment of a sentence were summarised to predict the total sentiment of that sentence (Hu and Liu 2004). 
In this study, this algorithm is being utilised to extract negative sentiments tweets from the all collected tweets.

\subsection{Descriptive analysis (DA)}

Twitter data consists of enormous amount of information, primarily tweets and user information (also known as metadata). DA looks after descriptive figures such as total number of tweets, total number of hashtags, and classification of tweets into different types. DA has been mentioned a lot in the research and practice of supply chain management. For instance, researchers describe the DA associated with the survey organized by them. The difference between the DA used by them and the one used in this study is in terms of number of metrics. Survey data has relatively small number of metrics (For example, size of sample, rate of response, etc.) whereas the sophisticated nature of twitter data assists in capturing intelligence via relatively large set of metrics like tweets, users, etc.

Tweet metrics aspires to highlight a basic but crucial idea of data by utilising various metrics (total number of tweets, total number of hashtags, etc.). These led to the evolution of other metrics. The information regarding the users posting tweets, replying to tweets and posting re-tweets is significant for both academic researchers analysing a particular topic and to industrial practitioners aiming to generate value for their trading. In this research, keywords and hashtag analysis are performed to extract the relevant tweet from twitter related to beef products.

Hashtags are an important part of tweets. They have the same role as the topic of interest used to categorise academic research papers. Analysis of hashtag consists of analysis of frequency and association rule mining. Analysis of frequency demonstrates how popular hashtags are. Association rule mining explores the relation between hashtags.

\subsection{Content analysis (CA)}

The data captured form above method is in the form of unstructured texts. Content Analysis (CA) offers a wide range of text capturing and Natural Language Processing (NLP) techniques for mining intelligence from Web 2.0 (Chau and $\mathrm{Xu}$ 2012). A tweet is an informal text and consists of few words, URLs, hashtags and certain other kinds of information. In order to extract intelligence, text cleaning and processing is necessary.

Text capturing and machine learning algorithms are vital ingredients of $\mathrm{CA}$. The unstructured texts could be transformed to structured texts by the utilisation of text capturing techniques such as n-grams, tokenization, etc. (Weiss et al. 2010). The transformed texts can then be utilised for analysis of keyword, summarisation of text, analysis of word frequency, clustering of texts by employing machine learning algorithms, like clustering and association analysis. CA has been mentioned in the literature of supply chain management as a manual or partial manual approach via human interpretations (Seuring and Gold 2012; Vallet-Bellmunt et al. 2011). In this article, CA is performed by automatic text processing methods.

Analysis of word is the first step in CA. It consists of summarization of document, term frequency, analysis of term frequency and clustering. Term frequency has been used a lot for information retrieval. It can be merged with n-gram, which assists in extracting key phrases from the document. They assists in distinguishing topic of interest, which are helpful for analysis at document level, by utilising machine learning algorithms such as clustering. Clustering at document level assists in document categorizing, which aids in thorough analysis of documents as per their categorisation. 


\subsection{Association of twitter data with waste in the supply chain}

The issues occurring at consumer end will be identified using above-mentioned twitter analytics tool. Thereafter, it will be associated with their root causes in the supply chain. The analysis of consumer tweets will assist in finding the issue, which are leading to the maximum amount of waste. Strengthening the coordination among the stakeholders in the supply chain could mitigate these issues.

\section{Data collection and analysis}

Twitter data is enormous considering about 500 million tweets per day. It is quite difficult to analyse all twitter data. In the literature, usually, analysis is performed over the information collected from twitter for certain time period. Thereafter, a data sampling process based on keyword and hashtag is performed to extract specific intelligence. There are two components of Application Programming Interface (API) to get access to public tweets, which are search API and streaming API. The search API will capture tweets from the past as per the criteria (hashtags, keywords, location, senders, etc.) (Bruns and Liang 2012). This method will only provide access to limited number of tweets. Streaming API can provide access to continuous stream of fresh tweets associated with specific keywords or related to specific location or users. In this research, twitter data related to customer dissatisfaction with beef products were collected using streaming API from January 2015 to January 2016.

\subsection{Data collection}

Initially, using the keyword 'beef' all the tweets related to beef products in the aforementioned period are collected. The sentiment analysis was performed on the collected tweets and only the tweets carrying negative scores were captured. Some examples of the negative tweets captured are shown in Table 1. A filtration criterion was deployed and only the tweets associated with consumers purchasing beef products and cooking them were considered. The tweets related to beef products served in a restaurant to consumers are not considered in this study. For instance, tweets like "When you buy @ Tesco beef mince and it goes off before its use by date!!!! No dinner \#smellymeat \#yuck !!!!!!!!” were considered and tweets such

Table 1 Examples of tweets with negative sentiments

\begin{tabular}{|c|c|}
\hline Sentiment Scores & Raw Tweets \\
\hline-1 & $\begin{array}{l}\text { @ AsdaServiceTeam why does my rump steak from asda Kingswood taste } \\
\text { distinctly of bleach please? }\end{array}$ \\
\hline-1 & $\begin{array}{l}\text { The beef lasagne from woolworths smells like sweaty armpits } \\
\text { siesð } \ddot{Y}^{\sim} \cdot \partial \ddot{Y}^{\sim} \cdot \partial \ddot{Y}^{\sim}\end{array}$ \\
\hline-1 & $\begin{array}{l}\text { @ Morrisons so you have no comment about the lack of meat in your } \\
\text { Family Steak Pie? \#morrisons }\end{array}$ \\
\hline-2 & $\begin{array}{l}\text { @ Tesco just got this from your D'ham Mkt store. It's supposed to be Men's } \\
\text { Health Beef Jerky...The smell is revolting https://t.co/vTKVRIARW5 }\end{array}$ \\
\hline-1 & $\begin{array}{l}\text { Buying corned beef from Aldi is an abomination. There are things you } \\
\text { cannot and should not buy from Aldi }\end{array}$ \\
\hline
\end{tabular}


as "piece of plastic in my Angus Beef burger. @ McDonalds \#chokinghazard \#mcdonalds \#angusbeef \#burger \#badfood https://t.co/2JHSkElQPH" were discarded.

Collected tweets are divided into five major issues at consumer end. The detailed descriptions of these issues are given in the following subsection.

\subsection{Description of issues occurring at consumer end}

During the interaction with retailers and consumers, it was found that all the consumer related complaints could be divided into five major subcategories related to discoloration of meat, hard texture, excess of fat, and presence of foreign body, bad smell and flavour. The detailed descriptions of these categories are described below:

1. Losing colour-Customers expect the beef product to be fresh red in colour. If beef products has transformed into grey, brown, etc while cooking or when the packet was opened they get annoyed and disappointed.

2. Hard texture-The beef products are expected to be tender and easy to cut. If the customers find it hard to chew even after cooking, they get dissatisfied. This kind of issues primarily arises in beef products derived from hindquarter of cattle like steak and joint. The softness of beef product plays a crucial role in increasing the customer satisfaction.

3. Excess of fat and gristle-Lean beef with minimum content of gristle is being desired by the customers. It could lead to disappointment if the beef products are not meeting customer expectations. If beef products have surplus of fat and gristle customer perceive that meat is not of high quality and not good for their health.

4. Bad flavour, smell and rotten-Good flavour, smell and fresh outlook are one of the prime selling point of the beef products. If they are bitter in taste or unexpectedly bad, it could lead to the beef products being discarded. Similarly, if their smell is poor and they looks rotten, then customers perceive them as inedible and dump them into the bin.

5. Foreign body-Customers expect only the fresh beef inside the packaging of beef products. In some of the cases, it was observed that some foreign bodies like piece of plastic, piece of metal, insect, mosquito have been identified in them. Customers perceive it as a food safety concern and discard them, which leads to waste.

In order to divide all collected tweets to above-mentioned categories, keywords are identified, which is explained in next subsection.

\subsection{Identification of keywords}

In order to divide the collected negative tweets into various categories as shown in Table 2, different keywords are identified. Initially, site visit was made to different retailer stores (both main and convenience stores) in the UK to explore the various kinds of complaints filed by customers regarding the beef products. The staff members dealing with customer complaints were interviewed. They provided access to their database of beef products related complaints. It will assist in identifying the keywords used by the customers corresponding to five major issues mentioned above. Few customers were also interviewed regarding the kind of complaints they are facing. The research team of this study also did some research on their own about the kinds of complaints left by customers in the stores. Various keywords used over the twitter are collected and they were discussed with waste minimisation team of retailer and customers. It helped to identify the keywords commonly used by the consumers associated with different types of issues highlighted above. The keywords and hashtags received from all three methods mentioned above are shown in Table 3. Thereafter, with the help of experts these keywords and hashtags are divided corresponding to five major issues 
Table 2 Highlighting issues occurring at consumer end and the associated keywords and hashtags

\begin{tabular}{|c|c|c|c|}
\hline S. no. & $\begin{array}{l}\text { Issues occurring at } \\
\text { consumer end }\end{array}$ & Keywords & Hashtags \\
\hline 1. & Losing colour & $\begin{array}{l}\text { discoloured, grey colour, odd colour, } \\
\text { funny colour, green colour }\end{array}$ & $\begin{array}{l}\text { \#odd colour, \#discoloured, } \\
\text { \#greycolour, \#funnycolour, \#green } \\
\text { colour }\end{array}$ \\
\hline 2. & Hard texture & chewy, hard, not tender & \#chewy, \#hard, \#nottender \\
\hline 3. & $\begin{array}{l}\text { Excess of fat and } \\
\text { gristle }\end{array}$ & fatty, gristle, oily, fat & \#fatty, \#gristle, \#oily, \#fat \\
\hline 4. & $\begin{array}{l}\text { Bad flavour, smell } \\
\text { and rotten }\end{array}$ & $\begin{array}{l}\text { awful taste, bad flavour, bitter, foul } \\
\text { smell, rancid, oxidised, rotten, } \\
\text { stink, taste, flavour, smell }\end{array}$ & $\begin{array}{l}\text { \#rotten, \#badflavour, \#stink, } \\
\text { \#awfultaste, \#rancid, \#oxidised, } \\
\text { \#rotten, \#bitter, \#foulsmell, \#taste, } \\
\text { \#smell, \#flavour }\end{array}$ \\
\hline 5. & Foreign body & $\begin{array}{l}\text { piece of plastic, packaging blown, } \\
\text { piece of metal, insect, mosquito, } \\
\text { foreign body }\end{array}$ & $\begin{array}{l}\text { \#pieceofplastic, \#insect, } \\
\text { \#pieceofmetal, \#foreignbody, } \\
\text { \#packgingblown, \#mosquito }\end{array}$ \\
\hline
\end{tabular}

Table 3 Keywords and hashtags used for extracting consumer tweets about complaints in beef products

\begin{tabular}{llll}
\hline discoloured & \#rotten & \#rancid & \#chewy \\
\#awfultaste & oxidised & \#packagingblown & odd colour \\
\#oddcolour & \#discoloured & \#pieceofplastic & \#gristle \\
grey colour & hard & \#oxidised & \#taste \\
\#flavour & \#smell & \#rotten & \#funnycolour \\
fatty & gristle & \#hard & chewy \\
awful taste & rotten & funny colour & rancid \\
\#grey colour & oily & fat & green colour \\
not tender & \#fatty & \#green colour & piece of plastic \\
insect & piece of metal & packaging blown & \#stink \\
\#foreignbody & \#nottender & \#fat & \#oily \\
\#pieceofmetal & \#insect & bad flavour & bitter \\
foul smell & stink & taste & flavour \\
smell & \#badflavour & \#bitter & \#foulsmell \\
mosquito & foreign body & \#mosquito & \\
\hline
\end{tabular}

as shown in Table 2. Further, tweets corresponding to these keywords are extracted from negative sentiment tweets and are used for further study.

In the tweets capture above, consumers are tweeting about variety of things like complaining, comparing different kinds of beef products like organic, inorganic, mince, burger, steak, joint, etc. Among the tweets, where name of beef products was mentioned, it was found that around $74 \%$ tweets were about steak, $12 \%$ tweets were associated with burger, $7 \%$ tweets were about mince, $4 \%$ tweets were about diced and stir fry products and $3 \%$ tweets were about other beef products such as offal, veal, escalope, etc. The tweets captured consists of various issues such as smell, taste, rotten, lack of tenderness, extra fat, discoloration, presence 
Table 4 Example of more than one hashtags used by consumers on Twitter

\begin{tabular}{lll}
\hline \#rancid\#foulsmell & \#badsmell\#awfulflavour & \#discoloration\#greycolour \\
\#chewy\#unpleasant & \#rotten\#disappointed & \#fatty\#gristle \\
\#insect\#foreignbody & \#browncolour\#gutted & \#plastic\#foodsafety \\
\#packagingblown\#piece & \#rancid\#flavourless & \#oxidised\#discoloured \\
\#pieceofmetal\#beef & & \\
\#smell\#steak\#rotten & \#oddcolour\#disappointed & \#beef\#hard\#gutted \\
\#beef\#greencolour\#bin & \#beef\#awfultaste\#chewy & \#fatty\#gristle\#steak \\
\#beef\#badflavour\#stinks & \#fatty\#beef\#gristle & \#beef\#chewy\#smell \\
\#steak\#discolored & \#beef\#rotten\#packagingblown & \#beef\#rancid\#awfultaste \\
\#disappointed & \#beef\#notenderness\#gutted & \#beef\#mince\#foulsmell \\
\#beef\#burger\#gristle & & \\
& \#beef\#oddcolour\#smell & \#steak\#fatty\#grsitle \\
\hline
\end{tabular}

of foreign body. The detailed analysis of collected tweets is performed using descriptive and content analysis.

\subsection{Descriptive analysis}

In the analysis, it was found that there were $88.5 \%$ of original tweets. In few cases, there were some retweets and replies as well. In $3.2 \%$ cases, retweets have occurred. It usually reflects the occurrence of major incidences in beef industry. While, $8.3 \%$ of cases consist of replies. It generally happens when another customer have faced similar situation or a customer in complaint has tagged a name of retailer. Further, analysis was performed to see how many cases hashtags were used. In the study, it was found that in $25 \%$ of cases, hashtags were used to express their concern. The most commonly used hashtags were \#disappointment, \#complaint, \#rotten, \#awful, \#notimpressed, \#inedible, \#unhappy, \#foodsafety. Sometimes, customers have used more than one hashtags. For example, if customer found grey colour and rancid smell in their beef product. Then, the dissatisfaction is usually expressed by hashtags like \#rancidbeef \#greycolourbeef. In $16.6 \%$ of cases, more than one hashtags is used to express their dissatisfaction. Some examples of more than one hashtags used are shown in Table 4. Sometimes, customers tag images to their tweets to express their anger and dissatisfaction. In $6.25 \%$ of cases, images were tagged with the tweets. In $51.2 \%$ of tweets, customers have also tagged the name of supermarket in their complaint.

\subsection{Content analysis}

It is composed of hashtag analysis and frequency analysis. These two analysis are being performed as following:

\subsubsection{Hashtag analysis}

Hashtags are employed to associate their opinion with a wider community of similar interest. For example, if a customer finds his/hers beef product to be inedible then he/she might use \#foodsafety to highlight this issue. They are employed before a keyword to assign the tweets to a certain category. It assists in searching of these tweets when the associated keywords 


\section{Distirbution of frequency of hashtag keywords}

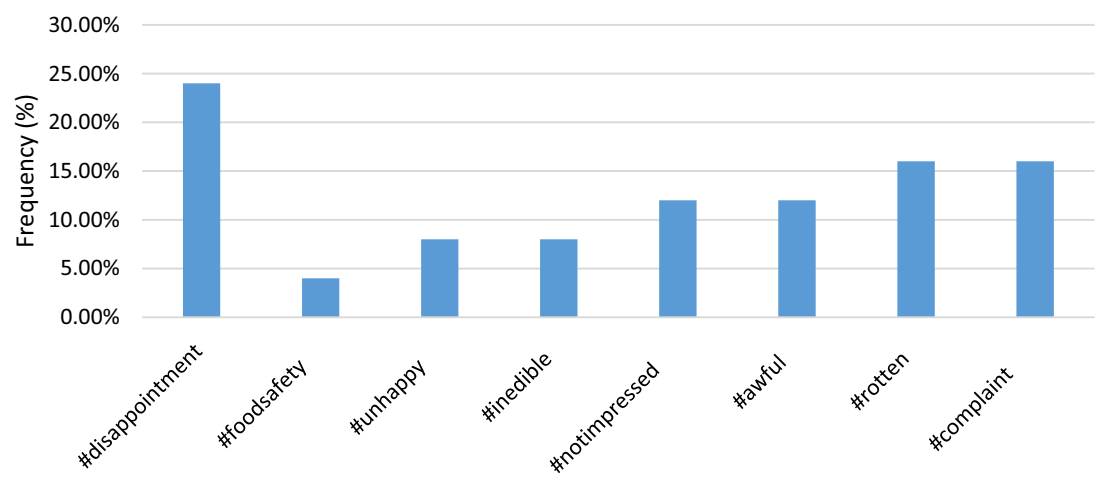

Fig. 4 Frequency distribution of hashtags

are searched in the twitter engine. When the word after hashtag is clicked, all the tweets made in the past consisting of that keyword are shown. Hashtag can be made at any position in the tweets like at the beginning, end or somewhere in the middle. Hashtag analysis was performed on all the collected consumer tweets. In experiment, it was found that $25 \%$ of the tweets were associated with different hashtags. The most widely used hashtags were: \#disappointment (24\%), \#complaint (16\%), \#rotten (16\%), \#awful (12\%), \#notimpressed (12\%), \#inedible (8\%), \#unhappy (8\%), \#foodsafety (4\%). Their distribution is shown in the bar chart in Fig. 4. Sometimes, more than one hashtags were used in a particular tweet. Most of the hashtags shown in the bar chart below are related to dissatisfaction rather than highlighting any specific issues apart from \#rotten, \#inedible and \#foodsafety. \#rotten is primarily related to food expiring prior to the expiry of their shelf life. It may be because of temperature abuse of the beef products or damage in packaging, which might lead to their shorter shelf life. While, \#indedible and \#foodsafety are very closely related to each other. These kinds of tweets are made when a foreign body like plastic, piece of metal, insect are found in the beef products. During the analysis, it was found that the most commonly used hashtag were \#rotten followed by \#inedible and \#foodsafety.

\subsubsection{Frequency analysis of waste categories}

All tweets are divided into five major issues using the keywords as shown in Table 2. The amount of customers' tweets corresponding to various issues is: Losing colour (12\%), Hard texture $(11.51 \%)$, Excess of fat and gristle $(22.7 \%)$, Bad flavour, smell and rotten $(18.5 \%)$, Foreign body $(35.29 \%)$. This distribution has been depicted in the Fig. 5. It is evident that 'Foreign body in beef products', 'Excess of fat and gristle' and 'Bad flavour, smell and rotten' are contributing to maximum amount of consumer complaints on twitter. These three are the major hotspots of customers' complaints. The preventive measures to minimise the waste is prescribed in next subsection.

\subsection{Root cause identification and waste mitigation strategy}

In the beef supply chain, highest amount of waste is generated at consumer end. It is caused due to various issues in the supply chain as shown in Fig. 6. The consumer tweets regarding 


\section{Distirbution of frequency of issues occurring at consumer end}

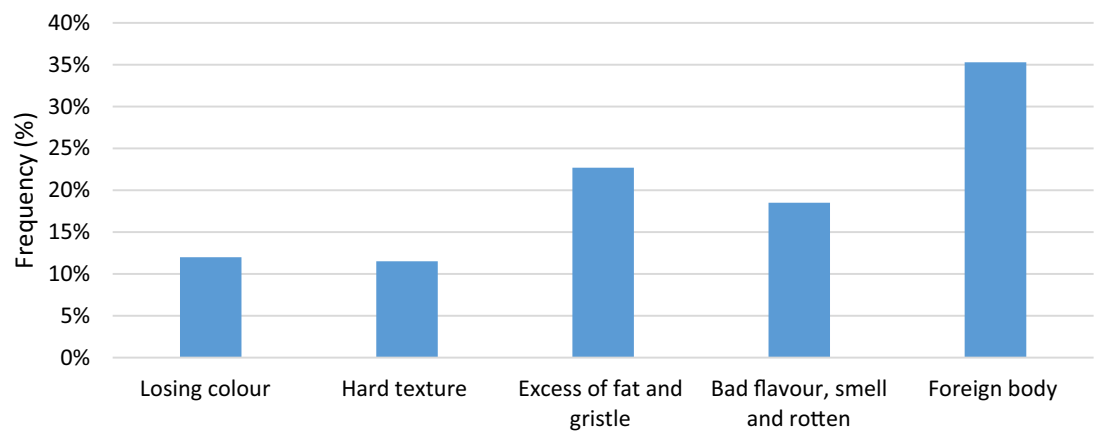

Fig. 5 Frequency distribution of issues occurring at consumer end

issues in beef products are vague in nature. They are not as accurate as the complaints made in the retail store, which consists of details like bar code, date of purchase, shelf life expiry, etc. The rich information available for specific complains made in retail store could be employed to find its exact root cause in the supply chain. However, this process could not be performed with that precision using social media data to pinpoint the exact issue in the supply chain as they are written in a very casual and short form and also they have a limit of 140 characters per tweet. Hence, using social media data only probable root causes of waste could be identified within the supply chain. These probable root causes of the waste (issues) and their preventive measure are being explained below:

a. Losing colour - Sometimes, beef products loses their colour before their shelf life is expired (Jeyamkondan et al. 2000; Renerre 1990). Consumers think that these products have gone past their shelf life and do not buy them, which is ultimately dumped as waste. The primary reason for this issue is that the cattle were not fed with fresh grass, which is rich in Vitamin $\mathrm{E}$ and helps to maintain fresh red colour for longer duration (Liu et al. 1995; Houben et al. 2000; Cabedo et al. 1998; Formanek et al. 1998; O’Grady et al. 1998; Lavelle et al. 1995; Mitsumoto et al. 1993). There could be other reasons contributing to discolouration of meat as well. The beef products might have been subjected to temperature abuse (Rogers et al. 2014; Jakobsen and Bertelsen 2000; Gill and McGinnis 1995; Eriksson et al. 2016). If they have been exposed to a temperature of more than three degree Celsius, they loses their fresh red colour prior to expiry of their shelf life (Rogers et al. 2014; van Laack et al. 1996; Jeremiah and Gibson 2001; Greer and Jones 1991). Therefore, to avoid the issue of discolouration of meat at consumer end, the cattle should be fed with fresh grass at beef farms and after getting processed into beef products, they should be kept at chilled temperature throughout the supply chain.

b. Hard texture-The tenderness of the beef products plays a crucial role in deciding their quality (Goodson et al. 2002). If the beef purchased by customers doesn't have enough tenderness and is not easy to chew while eating, it could disappoint the customers and would be discarded by them (Huffman et al. 1996). Usually, this issue occurs in steak and joint, which are derived from hindquarter of the cattle. The main root cause of this issue is that the carcass is not being matured properly after the cattle were slaughtered (Riley et al. 2005; Vitale et al. 2014; Franco et al. 2009; Gruber et al. 2006; Monsón et al. 2004; Sañudo et al. 2004; Troy and Kerry 2010). Maturation process refers to carcass being kept at chilled temperature for 
7-21 days depending on age, gender and breed of the cattle (Riley et al. 2005). Therefore, the beef should be matured properly in order to improve their tenderness.

c. Excess of fat and gristle-It was observed that beef products were having excess of fat instead of lean beef desired by customers. Hence, they get discarded as waste (Brunsø et al. 2005; Byers et al. 1993; Unnevehr and Bard 1993). The root cause of this issue lies in both beef farms and slaughterhouse. If the cattle are not raised to the weight and conformation specifications of the retailer, then the meat derived from them might be having excessive fat on them (Hanset et al. 1987; Herva et al. 2011; Borgogno et al. 2016; AHDB Industry Consulting 2008; Boligon et al. 2011). In the boning hall of slaughterhouse, if appropriate trimming procedures are not being followed then beef products are left with extra layer of fat (Francis et al. 2008; Mena et al. 2014; Kale et al. 2010; Watson 1994; Cox et al. 2007). The cattle should be raised in an optimum way to meet the weight and conformation specifications of retailer and proper trimming of primals should be performed in the boning hall. Customers often complain about too much gristle in beef products. The beef products derived from shoulder, chuck and legs should be processed through optimum butchering and boning techniques so that minimum amount of gristle is left in the meat cuts (Cobiac et al. 2003).

d. Bad flavour, smell and rotten-One of the major reason of bad flavour, smell and beef products becoming rotten is their oxidisation i.e. their exposure to air resulting in oxidisation of lipids and proteins (Brooks 2007; Campo et al. 2006; Utrera and Estévez 2013; Wang and Xiong 2005). Consumers perceive these products as inedible and dump them into the bin. The root cause of this issue lies in the packaging of beef products. They might not be packed properly at abattoir and processor, the packaging might be damaged at some stage in the supply chain and inappropriate packaging method might be used causing premature oxidisation of the beef products (Barbosa-Pereira et al. 2014; Brooks 2007). Regular maintenance of packaging machines, random sampling of beef products and use of modern packaging technology, which delays oxidisation of beef products like Vacuum Skin Packaging (Cunningham 2008) could assist in mitigating this issue at abattoir and processor end. The staff in the retailer store must be properly trained so that the mishandling of beef products does not damage the packaging. Another significant issue leading to bad smell, flavour and making beef products rotten is failure of cold chain (James and James 2002, 2010; Raab et al. 2011). It is very important to maintain a chilled temperature of 1-3 degree Celsius for beef products throughout the supply chain whether it is at abattoir, processor, logistics or retailer (Kim et al. 2012; Mena et al. 2011). The inefficient cold chain management could be due to lack of periodic maintenance of refrigeration equipment (Kim et al. 2012). Therefore, efficient cold chain management must be maintained for the whole beef supply chain to avoid the wastage of beef products. There should be periodic temperature checks performed at various stages in the supply chain to ensure that appropriate temperature is being maintained for the efficient product flow of the beef products.

e. Foreign bodies - In some of the rare cases, foreign bodies like plastic, piece of metal, insect have been found on the beef products or damaged packaging (FSA 2015). Customers perceive these beef products as inedible and dump them into the bin. The root cause of this issue lies in the inefficiency of machines doing the packaging at abattoir and processor, lack of safety checks like metal detection, physical inspection, lack of renowned process management technique for food safety such has HACCP, etc (Goodwin 2014; Lund et al. 2007; Jensen et al. 1998; Piggott and Marsh 2004). There should be regular maintenance of the packaging machines and random sampling of beef products performed at their premises. Appropriate 


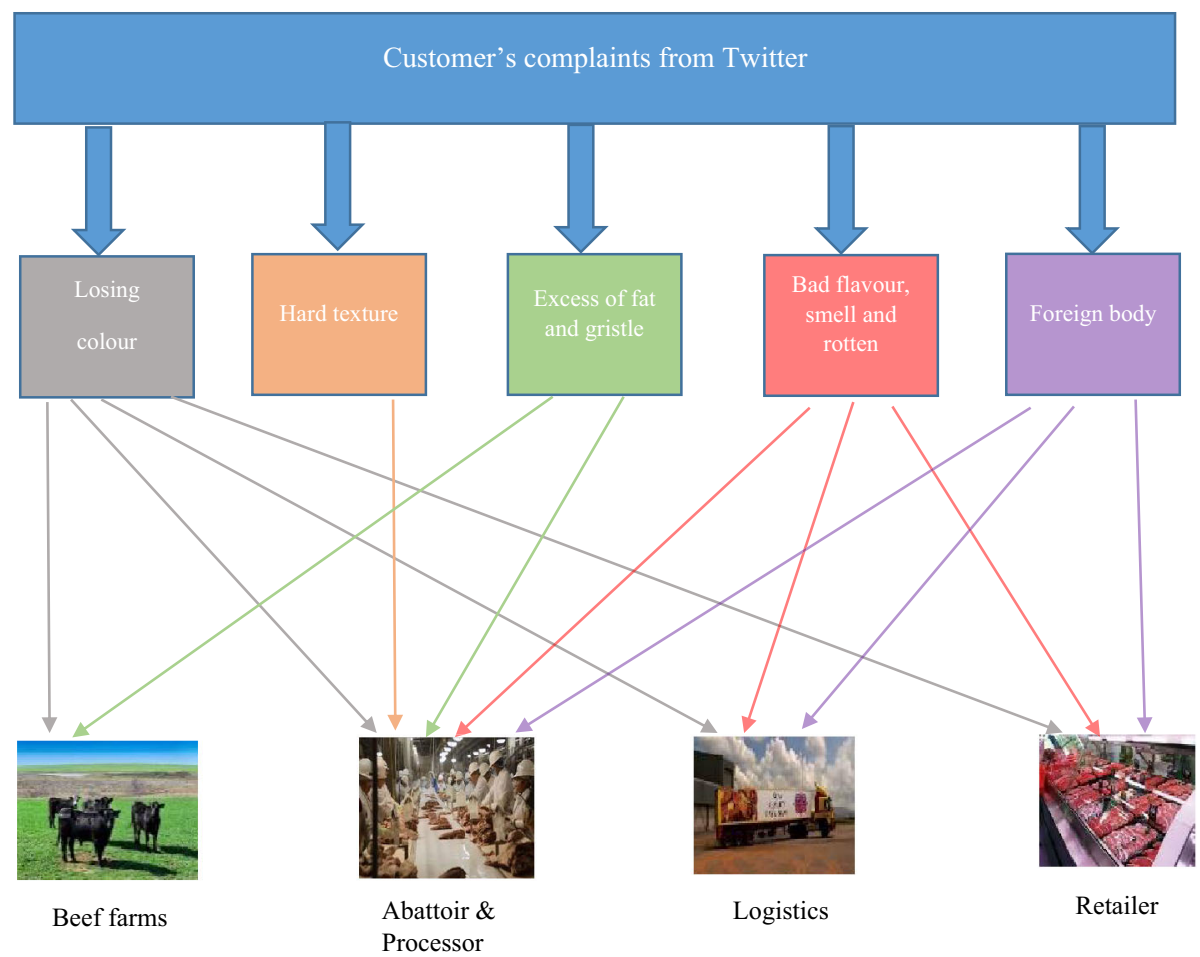

Fig. 6 Association of issues occurring at consumer end with various stakeholders of beef supply chain

safety checks like metal detection, physical inspection, should also be performed at various stages in abattoir and processor and a well-established food safety process management procedures like HACCP, GMP, must be followed address to this issue (Bolton et al. 2001; Goodwin 2014; Roberts et al. 1996). The beef products also damage by mishandling within the supply chain (Goodwin 2014; Singh et al. 2015). The workforce working at premises of all the stakeholders must be appropriately trained and supervised to address this issue. There should be quality checks performed at various stages in the supply chain so that beef products consisting of foreign bodies like piece of metal and insects are discarded prior to being sold to the consumers.

In the next section, managerial implications of proposed framework has been described in detail.

\section{Managerial implications}

Complaints associated with the food products are a critical issue for major retailers both because of loss of revenue and also it affects their reputation. It might also lead to loss of customers. Complaints in the food products lead to food waste, which raises a moral question considering there are millions of people losing their lives because of scarcity of food, across the world. Food waste and the complaints associated with them are a cause of concern for the whole world. Various retailers are employing different strategies to mitigate the food waste 
and reduce the amount of complaints being received from customers. They have given the opportunity to customers to make complaints about food products if they are not satisfied with them. However, all unhappy customers didn't make complaints in the retail store. Instead, majority of them express their dissatisfaction on social media like twitter. Often, they tag the name of the retailer while tweeting their complaints. Hence, the long-term reputation of retailers is at stake. The complaints made by consumers on social media are vague and unstructured in nature. In the past, there was no mechanism available to link them with the root causes of waste in various segments of supply chain. The proposed methodology will assist the manager of food retailers to extract all the complaints posted on twitter. It will help them to identify the root causes of these complaints within their supply chain, which can be mitigated and consequently lead to waste minimisation of food products. The proposed methodology in this study will help them to extract more useful data with respect to customer complaints and help them to make their supply chain more robust.

The major issues revealed by customer's tweets helps to identify their root causes in supply chain. It can be at the premises of a stakeholder, at the interface of two stakeholders or at multiple places in the supply chain. The proposed framework in this study will help the policy makers of the retailer to prioritize the mitigation of various issues as per their impact on food waste. Normally, all the stakeholders in a beef supply chain work independently. If a common issue is identified in the whole supply chain leading to the waste in the customer end then the retailer can assist all the stakeholders to improve their coordination (in terms of information sharing) and collectively address this issue. The improved coordination among stakeholders will not just help in waste minimisation but assist in improved product flow, efficiency and sustainability of the supply chain. These aspects would be beneficial for both the retailer firms and the society.

\section{Conclusion}

Rising population is a cause of concern globally as there are limited resources (land, water, etc.) to produce food for them. Millions of people are dying worldwide because of being deprived from food. These complications cannot be mitigated alone by development of innovative technologies to extract more harvest from the limited natural resources. Waste minimisation must be made a priority throughout the food supply chain including their consumption at consumers' end. Food waste financially affects all the stakeholders of food supply chain viz. farmers, food processors, wholesalers, retailers, and consumers. Majority of waste is being generated at consumer end. Often, consumers are not happy with the food products and discard them. Apart from food waste, retailers are losing their customers because of their dissatisfaction. Although, major retailers have made a provision for the customers to make a complaint in the store, still, customers are not doing so. They are using social media like twitter to express their disappointment. Consumers usually tag the name of the retailer while making their complaints on social media, which is affecting the reputation of the retailers. There is plenty of useful information available on twitter, which can be used by food retailers for developing their waste minimisation strategy. This information is big in size considering its volume, variety and velocity. However, the consumer complaints posted on twitter (social media) are vague and unstructured in nature. In literature, there was no framework available to link them with root causes of waste at different segments in food supply chain. In the proposed methodology, customers' tweets associated with complaints of beef products are being extracted and sorted into five categories. These individual issues occurring at 
customer's end were then linked to their respective root causes in the beef supply chain. The root causes can be mitigated to reduce the food waste, improve the satisfaction of customers and their loyalty, and improve brand value of retailer and consequently financial revenue of the retailer. In future, an enhanced list of keywords could be used for further analysis of the issue. Twitter analytics could be employed for longer time duration and could be applied to other domains of food supply chain like lamb supply chain or any other food supply chain.

Acknowledgements The authors would like to thank the project 'A cross country examination of supply chain barriers on market access for small and medium firms in India and UK' (Ref no: PM130233) funded by British Academy, UK for supporting this research.

Open Access This article is distributed under the terms of the Creative Commons Attribution 4.0 International License (http://creativecommons.org/licenses/by/4.0/), which permits unrestricted use, distribution, and reproduction in any medium, provided you give appropriate credit to the original author(s) and the source, provide a link to the Creative Commons license, and indicate if changes were made.

\section{References}

AHDB Industry Consulting. (2008). Review of the EU carcase classification system for beef and sheep (EPES 0708/01). Retrieved from http://webarchive.nationalarchives.gov.uk/20130123162956, http:// www.defra.gov.uk/evidence/economics/foodfarm/reports/carcaseclassification/Full\%20Version.pdf.

Barbosa-Pereira, L., Aurrekoetxea, G. P., Angulo, I., Paseiro-Losada, P., \& Cruz, J. M. (2014). Development of new active packaging films coated with natural phenolic compounds to improve the oxidative stability of beef. Meat Science, 97(2), 249-254.

Boligon, A. A., Mercadante, M. E. Z., \& Albuquerque, L. G. D. (2011). Genetic associations of conformation, finishing precocity and muscling visual scores with mature weight in Nelore cattle. Meat Science, 135(2), 238-243.

Bolton, D. J., Doherty, A. M., \& Sheridan, J. J. (2001). Beef HACCP: Intervention and non-intervention systems. International Journal of Food Microbiology, 66(1), 119-129.

Borgogno, M., Saccà, E., Corazzin, M., Favotto, S., Bovolenta, S., \& Piasentier, E. (2016). Eating quality prediction of beef from Italian Simmental cattle based on experts' steak assessment. Meat Science, 118, $1-7$.

Brooks, C. (2007). Beefpackaging. Beeffacts products enhancement. Retrieved from http://www.beefresearch. org/CMDocs/BeefResearch/PE_Fact_Sheets/Beef_Packaging.pdf.

Bruns, A., \& Liang, Y. E. (2012). Tools and methods for capturing Twitter data during natural disasters. First Monday, 17(4), 1-8.

Brunsø, K., Bredahl, L., Grunert, K. G., \& Scholderer, J. (2005). Consumer perception of the quality of beef resulting from various fattening regimes. Meat Science, 94(1), 83-93.

Byers, F. M., Turner, N. D., \& Cross, H. R. (1993). Meat products in low-fat diet. In A. M. Altschul (Ed.), Low-calorie foods handbook (pp. 343-375). New York: Marcel Dekker Inc.

Cabedo, L., Sofos, J. N., \& Smith, G. C. (1998). Bacterial growth in ground beef patties made with meat from animals fed diets without or with supplemental vitamin E. Journal of Food Protection ${ }^{\circledR}, 61(1)$, 36-40.

Campo, M. M., Nute, G. R., Hughes, S. I., Enser, M., Wood, J. D., \& Richardson, R. I. (2006). Flavour perception of oxidation in beef. Meat Science, 72(2), 303-311.

Chae, B. K. (2015). Insights from hashtag\# supplychain and Twitter analytics: Considering Twitter and Twitter data for supply chain practice and research. International Journal of Production Economics, 165, 247259.

Chau, M., \& Xu, J. (2012). Business intelligence in blogs: Understanding consumer interactions and communities. MIS Quarterly, 36(4), 1189-1216.

Cicatiello, C., Franco, S., Pancino, B., \& Blasi, E. (2016). The value of food waste: An exploratory study on retailing. MIS Quarterly, 30, 96-104.

Cobiac, L., Droulez, V., Leppard, P., \& Lewis, J. (2003). Use of external fat width to describe beef and lamb cuts in food composition tables. Journal of Food Composition and Analysis, 16(2), 133-145.

Cox, A., \& Chicksand, D. (2005). The limits of lean management thinking: Multiple retailers and food and farming supply chains. European Management Journal, 23(6), 648-662. 
Cox, A., Chicksand, D., \& Palmer, M. (2007). Stairways to heaven or treadmills to oblivion? Creating sustainable strategies in red meat supply chains. European Management Journal, 109(9), 689-720.

Cunningham, S. B. (2008). The benefits of oxygen scavenging technology on overwrapped beef cuts in a modified atmosphere package. Ann Arbor: ProQuest.

Das, S, \& Chen, M. (2001). Yahoo! for Amazon: Extracting market sentiment from stock message boards. In Proceedings of APFA-2001.

Dave, K., Lawrence, S., \& Pennock, D. M. (2003). Mining the peanut gallery: Opinion extraction and semantic classification of product reviews. Proceedings of the 12th international conference on World Wide Web (pp. 519-528). New York: ACM.

Eriksson, M., Strid, I., \& Hansson, P. A. (2016). Food waste reduction in supermarkets-Net costs and benefits of reduced storage temperature. Resources, Conservation and Recycling, 107, 73-81.

Food Standards Agency (2012a). Food certification and assurance schemes. Retrieved from https://www.gov. uk/guidance/kitemarks-in-farmed-meat-and-produce.

Food Standards Agency (2012b). Food Law Code of practice (England). Retrieved from http://www.food.gov. uk/sites/default/files/multimedia/pdfs/codeofpracticeeng.pdf.

Formanek, Z., Kerry, J. P., Buckley, D. J., Morrissey, P. A., \& Farkas, J. (1998). Effects of dietary vitamin E supplementation and packaging on the quality of minced beef. Meat Science, 50(2), 203-210.

Francis, M., Simons, D., \& Bourlakis, M. (2008). Value chain analysis in the UK beef foodservice sector. Meat Science, 13(1), 83-91.

Franco, D., Bispo, E., González, L., Vázquez, J. A., \& Moreno, T. (2009). Effect of finishing and ageing time on quality attributes of loin from the meat of Holstein-Fresian cull cows. Meat Science, 83(3), 484-491.

Frizzo- Barker, J., Chow-White, P. A., Mozafari, M., \& Ha, D. (2016). An empirical study of the rise of big data in business scholarship. International Journal of Information Management, 36, 403-413.

FSA reports: Incident Report 2015 (2015). Retrieved from https://www.food.gov.uk/sites/default/files/annualreport-incidents-2015.pdf.

Gill, C. O., \& McGinnis, J. C. (1995). The effects of residual oxygen concentration and temperature on the degradation of the colour of beef packaged under oxygen-depleted atmospheres. Meat Science, 39(3), 387-394.

Goodson, K. J., Morgan, W. W., Reagan, J. O., Gwartney, B. L., Courington, S. M., Wise, J. W., et al. (2002). Beef customer satisfaction: Factors affecting consumer evaluations of clod steaks. Journal of Animal Science, 80(2), 401-408.

Goodwin, D. (2014). Foreign body contamination and the implications for the food manufacturing sector. Newfood. Retrieved from http://www.newfoodmagazine.com/advent-calendar/foreign-bodycontamination/.

Greer, G. G., \& Jones, S. D. M. (1991). Effects of lactic acid and vacuum packaging on beef processed in a research abattoir. Journal of Animal Science, 24(3), 161-168.

Gruber, S. L., Belk, K. E., Tatum, J. D., Scanga, J. A., \& Smith, G. C. (2006). Industry guide for beef aging. Centennial, CO: National Cattlemen's Beef Association.

Hanset, R., Michaux, C., \& Stasse, A. (1987). Relationships between growth rate, carcass composition, feed intake, feed conversion ratio and income in four biological types of cattle. Journal of Animal Science, $19(2), 1$.

Hazen, B. T., Boone, C. A., Ezell, J. D., \& Jones-Farmer, L. A. (2014). Data quality for data science, predictive analytics, and big data in supply chain management: An introduction to the problem and suggestions for research and applications. International Journal of Production Economics, 154, 72-80.

Hazen, B. T., Skipper, J. B., Boone, C. A., \& Hill, R. R. (2016). Back in business: Operations research in support of big data analytics for operations and supply chain management. Annals of Operations Research. doi:10.1007/s10479-016-2226-0.

Herva, T., Huuskonen, A., Virtala, A. M., \& Peltoniemi, O. (2011). On-farm welfare and carcass fat score of bulls at slaughter. International Journal of Production Economics, 138(1), 159-166.

Houben, J. H., Van Dijk, A., Eikelenboom, G., \& Hoving-Bolink, A. H. (2000). Effect of dietary vitamin E supplementation, fat level and packaging on colour stability and lipid oxidation in minced beef. Meat Science, 55(3), 331-336.

Hu, M., \& Liu, B. (2004). Mining and summarizing customer reviews. In Proceedings of ACM SIGKDD international conference on knowledge discovery and data mining (KDD-2004).

Huffman, K. L., Miller, M. F., Hoover, L. C., Wu, C. K., Brittin, H. C., \& Ramsey, C. B. (1996). Effect of beef tenderness on consumer satisfaction with steaks consumed in the home and restaurant. Journal of Animal Science, 74(1), 91-97.

Jakobsen, M., \& Bertelsen, G. (2000). Colour stability and lipid oxidation of fresh beef. Development of a response surface model for predicting the effects of temperature, storage time, and modified atmosphere composition. Meat Science, 54(1), 49-57. 
James, S. J., \& James, C. (2010). The food cold-chain and climate change. Food Research International, 43(7), 1944-1956.

James, S. J., \& James, C. B. (2002). Meat refrigeration. Amsterdam: Elsevier.

Jensen, H. H., Unnevehr, L. J., \& Gomez, M. I. (1998). Costs of improving food safety in the meat sector. Journal of Agricultural and Applied Economics, 30(01), 83-94.

Jeremiah, L. E., \& Gibson, L. L. (2001). The influence of storage temperature and storage time on color stability, retail properties and case-life of retail-ready beef. Food Research International, 34(9), 815-826.

Jeyamkondan, S., Jayas, D. S., \& Holley, R. A. (2000). Review of centralized packaging systems for distribution of retail-ready meat. Journal of Food Protection, 63(6), 796-804.

Kale, M. C., Aydın, E., Aral, Y., \& Cevger, Y. (2010). The research on investigation of factors affecting the production process on cattle slaughtering line in a private sector slaughterhouse. Journal of Food Protection, 57(3), 179-183.

Kaplan, A. M., \& Haenlein, M. (2011). Two hearts in three-quarter time: How to waltz the social media/viral marketing dance. Business Horizons, 54(3), 253-263.

Katajajuuri, J. M., Silvennoinen, K., Hartikainen, H., Heikkilä, L., \& Reinikainen, A. (2014). Food waste in the Finnish food chain. Journal of Cleaner Production, 73, 322-329.

Kim, Y. A., Jung, S. W., Park, H. R., Chung, K. Y., \& Lee, S. J. (2012). Application of a prototype of microbial time temperature indicator (TTI) to the prediction of ground beef qualities during storage. Journal of Cleaner Production, 32(4), 448-457.

Lavelle, C. L., Hunt, M. C., \& Kropf, D. H. (1995). Display life and internal cooked color of ground beef from vitamin E-supplemented steers. Journal of Food Science, 60(6), 1175-1178.

Laville, E., Sayd, T., Morzel, M., Blinet, S., Chambon, C., Lepetit, J., et al. (2009). Proteome changes during meat aging in tough and tender beef suggest the importance of apoptosis and protein solubility for beef aging and tenderization. Journal of Agricultural and Food Chemistry, 57(22), 10755-10764.

Liu, Q., Lanari, M. C., \& Schaefer, D. M. (1995). A review of dietary vitamin E supplementation for improvement of beef quality. Journal of Animal Science, 73(10), 3131-3140.

Lund, M. N., Hviid, M. S., \& Skibsted, L. H. (2007). The combined effect of antioxidants and modified atmosphere packaging on protein and lipid oxidation in beef patties during chill storage. Meat Science, $76(2), 226-233$.

Meat Industry Guide (2015a). Chapter 9 HACCP. Retrieved from https://www.food.gov.uk/sites/default/files/ Chapter9-HACCP-Principles.pdf.

Meat Industry Guide (2015b). Chapter 17 Wrapping, packaging and transport hygiene. Retrieved from https:// www.food.gov.uk/sites/default/files/Chapter17-Wrapping\%2CPacking\%26TransportHygiene.pdf.

Mena, C., Adenso-Diaz, B., \& Yurt, O. (2011). The causes of food waste in the supplier-retailer interface: Evidences from the UK and Spain. Resources, Conservation and Recycling, 55(6), 648-658.

Mena, C., Terry, L. A., Williams, A., \& Ellram, L. (2014). Causes of waste across multi-tier supply networks: Cases in the UK food sector. International Journal of Production Economics, 152, 144-158.

Miller, G. A., Beckwith, R., Fellbaum, C., Gross, D., \& Miller, K. (1990). WordNet: An on-line lexical database . Oxford: Oxford Univ Press.

Mitsumoto, M., Arnold, R. N., Schaefer, D. M., \& Cassens, R. G. (1993). Dietary versus postmortem supplementation of vitamin $\mathrm{E}$ on pigment and lipid stability in ground beef. Journal of Animal Science, 71(7), $1812-1816$.

Monsón, F., Sañudo, C., \& Sierra, I. (2004). Influence of cattle breed and ageing time on textural meat quality. Meat Science, 68(4), 595-602.

Nabhani, F., \& Shokri, A. (2009). Reducing the delivery lead time in a food distribution SME through the implementation of six sigma methodology. Meat Science, 20(7), 957-974.

Nasukawa, T., \& Yi, J. (2003). Sentiment analysis: Capturing favorability using natural language processing. Proceedings of the 2nd international conference on Knowledge capture (pp. 70-77). New York: ACM.

O'Grady, M. N., Monahan, F. J., Bailey, J., Allen, P., Buckley, D. J., \& Keane, M. G. (1998). Colour-stabilising effect of muscle vitamin E in minced beef stored in high oxygen packs. Meat Science, 50(1), 73-80.

Piggott, N. E., \& Marsh, T. L. (2004). Does food safety information impact US meat demand? American Journal of Agricultural Economics, 86(1), 154-174.

Raab, V., Petersen, B., \& Kreyenschmidt, J. (2011). Temperature monitoring in meat supply chains. American Journal of Agricultural Economics, 113(10), 1267-1289.

Red tractor assurance for farms (2011). Beef and Lamb standards. Retrieved from http://www.assuredfood. co.uk/resources/000/617/999/Beef_Lamb_standard.pdf.

Renerre, M. T. (1990). Factors involved in the discoloration of beef meat. American Journal of Agricultural Economics, 25(6), 613-630. 
Riley, D. G., Johnson, D. D., Chase, C. C., West, R. L., Coleman, S. W., Olson, T. A., et al. (2005). Factors influencing tenderness in steaks from Brahman cattle. American Journal of Agricultural Economics, 70(2), 347-356.

Roberts, T., Buzby, J. C., \& Ollinger, M. (1996). Using benefit and cost information to evaluate a food safety regulation: HACCP for meat and poultry. American Journal of Agricultural Economics, 78(5), 12971301.

Rogers, H. B., Brooks, J. C., Martin, J. N., Tittor, A., Miller, M. F., \& Brashears, M. M. (2014). The impact of packaging system and temperature abuse on the shelf life characteristics of ground beef. American Journal of Agricultural Economics, 97(1), 1-10.

Rutsaert, P., Regan, Á., Pieniak, Z., McConnon, Á., Moss, A., Wall, P., et al. (2013). The use of social media in food risk and benefit communication. American Journal of Agricultural Economics, 30(1), 84-91.

Sañudo, C., Macie, E. S., Olleta, J. L., Villarroel, M., Panea, B., \& Albert1, P. (2004). The effects of slaughter weight, breed type and ageing time on beef meat quality using two different texture devices. Meat Science, 66(4), 925-932.

Save Food. (2015) Global Initiative on Food Loss and Waste Reduction. Food and Agriculture Organization of the United Nations. Retrieved from http://www.fao.org/save-food/resources/keyfindings/en/.

Seuring, S., \& Gold, S. (2012). Conducting content-analysis based literature reviews in supply chain management. Meat Science, 17(5), 544-555.

Shuihua, H., Yufang, F., Bin, C., \& Zongwei, L. (2016). Pricing and bargaining strategy of e-retail under hybrid operational patterns. Annals of Operations Research. doi:10.1007/s10479-016-2214-4.

Singh, A., Mishra, N., Ali, S. I., Shukla, N., \& Shankar, R. (2015). Cloud computing technology: Reducing carbon footprint in beef supply chain. International Journal of Production Economics, 164, 462-471.

Sofos, J. N., Kochevar, S. L., Bellinger, G. R., Buege, D. R., Hancock, D. D., Ingham, S. C., et al. (1999). Sources and extent of microbiological contamination of beef carcasses in seven United States slaughtering plants. Journal of Food Protection ${ }^{\circledR}, 62(2), 140-145$.

Song, M. L., Fisher, R., Wang, J. L., \& Cui, L. B. (2016). Environmental performance evaluation with big data: Theories and methods. UK: Annals of Operations Research.

Tan, K. H., Zhan, Y., Ji, G., Ye, F., \& Chang, C. (2015). Harvesting big data to enhance supply chain innovation capabilities: An analytic infrastructure based on deduction graph. International Journal of Production Economics, 165, 223-233.

Tayal, A., \& Singh, S. P. (2016). Integrating big data analytic and hybrid firefly-chaotic simulated annealing approach for facility layout problem. Annals of Operations Research. doi:10.1007/s10479-016-2237-x.

Taylor, D. H. (2006). Strategic considerations in the development of lean agri-food supply chains: A case study of the UK pork sector. International Journal of Production Economics, 11(3), 271-280.

Thackeray, R., Neiger, B. L., Smith, A. K., \& Van Wagenen, S. B. (2012). Adoption and use of social media among public health departments. International Journal of Production Economics, 12(1), 1.

Troy, D. J., \& Kerry, J. P. (2010). Consumer perception and the role of science in the meat industry. International Journal of Production Economics, 86(1), 214-226.

Twitter Usage Statistics, 2016. Retrieved from http://www.internetlivestats.com/twitter-statistics/.

Unnevehr, L. J., \& Bard, S. (1993). Beef quality: Will consumers pay for less fat? Journal of Agricultural and Resource Economics, 18, 288-295.

Utrera, M., \& Estévez, M. (2013). Oxidative damage to poultry, pork, and beef during frozen storage through the analysis of novel protein oxidation markers. International Journal of Production Economics, 61(33), 7987-7993.

Vallet-Bellmunt, T., Martínez-Fernández, M. T., \& Capó-Vicedo, J. (2011). Supply chain management: A multidisciplinary content analysis of vertical relations between companies, 1997-2006. Industrial Marketing Management, 40(8), 1347-1367.

van Laack, R. L., Berry, B. W., \& Solomon, M. B. (1996). Effect of precooking conditions on color of cooked beef patties. Journal of Food Protection®, 59(9), 976-983.

Vera-Baquero, A., Colomo-Palacios, R., \& Molloy, O. (2016). Real-time business activity monitoring and analysis of process performance on big-data domains. Telematics and Informatics, 33(3), 793-807.

Vitale, M., Pérez-Juan, M., Lloret, E., Arnau, J., \& Realini, C. E. (2014). Effect of aging time in vacuum on tenderness, and color and lipid stability of beef from mature cows during display in high oxygen atmosphere package. Telematics and Informatics, 96(1), 270-277.

Wang, L. L., \& Xiong, Y. L. (2005). Inhibition of lipid oxidation in cooked beef patties by hydrolyzed potato protein is related to its reducing and radical scavenging ability. Journal of Agricultural and Food Chemistry, 53(23), 9186-9192.

Wang, G., Gunasekaran, A., \& Ngai, E. W.T. (2016). Distribution network design with big data: Model and analysis. Annals of Operations Research. doi:10.1007/s10479-016-2263-8. 
Watson, M. J. (1994). Fostering leaner red meat in the food supply. Journal of Agricultural and Food Chemistry, 96(8), 24-32.

Weiss, S. M., Indurkhya, N., Zhang, T., \& Damerau, F. (2010). Text mining: Predictive methods for analyzing unstructured information. New York: Springer Science \& Business Media. 